quate printout, and there is support from them.

Finally, it should be observed that a new library finds itself setting policy on different matters almost every day. This calls for a careful examination of the old way of doing things and consideration of the newest way.

\title{
The Computerized Book Catalog At Florida Atlantic University
}

\section{By JEAN M. PERREAULT}

IN THE AUTOMATION of library work (or, if you will, its computerization) the catalog must be considered one of the primary targets. One of the principal concerns of the extensive research at the Chicago campus library of the University of Illinois, resulting in the treatise Advanced Data Processing in the University $\mathrm{Li}$ brary, ${ }^{1}$ was the preparation of an outline of what could be done to bring the catalog into the frame of reference of the computer. The research of the University of Illinois, Chicago staff and their General Electric consultants was primarily theoretical. The research was essential but it by no means automatically brought about the solution of the problem. This solution is not directed primarily toward any new problems; it is and must be a solution for the same problems that always have been with every cataloger. But often the presence of these problems has been almost ignored because of an accumulation of too-easy, halfway solutions to dimly seen problems. Automation has the inestimable advantage over any conventional cataloging system. It cannot allow solutions which do not solve because they do not need to-their users will keep them from succumbing to their own unexamined flaws. Automation cannot allow any such "system-flaws," because when such a system is turned over to a computer for manipulation, it will give results which re-

1 (New York : Searecrow Press, 1962.)
Mr. Perreault is Chief of Cataloging in Florida Atlantic University in Boca Raton.

flect precisely the degree of intensity given to the solution of problems before they arise. Systems-design is an activity worth all the time any cataloger can give to it, even those who have no intention of investing in computer hardware.

The configuration of the input document as designed by the staff of the University of Illinois, Chicago library can be described as a "bibliographic string" modeled on the tradition of cataloging at present embodied in ALA and LC cataloging rules, but with the addition to this string of "knots" occurring wherever a new element begins. These knots are symbolized on the input document in a series of numbers representing to the computer the function of the element of the catalogtext that is associated with it.

In the course of a great many conferences, notably with Louis Schultheiss of the University of Illinois, Chicago library staff and with Frederick Kilgour of the Yale medical library, several important modifications were developed in the Florida Atlantic University form of cataloging for computer manipulation. Each area of the input document was reduced to the crucial length below which reductions would begin to affect a considerable number of entries in such a way as to reduce their fullest usefulness. Flexibility was a 
consideration wherever it was called for, short of the extreme of a printed form without internal articulation, as in the form adopted by the Columbia-HarvardYale medical union-cataloging project. This in effect takes all the knots out of the bibliographic string.

Together with these modifications, however, the Florida Atlantic University staff developed a casual suggestion by Mr. Schultheiss into a totally new system. This new system aims at a relaxation of the over-rigidly articulated University of Illinois, Chicago system, while remaining "knotted." The basic suggestion was to eliminate the various pre-assigned areas for the several types of main entry (each with its own code number, or knot), indicating in some other field of the input document which of the types was appropriate to that particular entry. This has resulted in the imprint-collation area in the Florida Atlantic University system being coded with just one "knot" rather than the several intended by the original outline (i.e., that first designed by the Florida Atlantic University staff in close similarity to the University of Illinois, Chicago design: one each for place, publisher, date, pagination, size, all the various collational elements, series notes, other notes). In turn, each of these elements, if judged worthy of later retrievability, is entered in a separate area in coded form (for some elements as a numerical code, for the rest as a yes/no check; this technique is more fully considered in this issue in the article by Clayton D. Highum entitled "Cataloging for Document Retrieval at Florida Atlantic University").

Following are a few examples of Florida Atlantic University input documents filled in, and then as embodied.

FLoRIDa AtLantic University

LibraRy Catalog InPUT Record: A

Sample of Its PlanNed Results

Example 1 shows the input document for a simple work with conventional title; note that area 23 ("Die Verteidigung ...") does not trace out, since it has been made a see-reference to "The maiden's rescue," in a separate operation (i.e., authority-file maintenance). Note that the Luhn-number is assigned for the convenience of the requestor, and does not necessarily correspond to the cataloger's decision as to the correct main entry.

Example 2 shows the embodiments that result from the input document; $e x-$ ample 3 shows that the collation code is stored on magnetic tape along with the descriptive and subject cataloging, in shelflist order, for future document retrieval purposes.

Example 4 shows the input document for a complex work; note that excess lines have been used in areas 23 and 31 only because of non-use of an equal number of lines in areas 70, 76, and 78; note the use of the double asterisk $(* *)$ in area 23 ; note also that here again the Luhnnumber is assigned for the convenience of the requestor.

Example 5 shows the embodying author catalog entries; example 6 those for the title catalog; example 7 those for the subject catalog.

Example 8 shows the input document for an analytical entry (one of, supposedly, many from the same work shown in examples 4-7). Note that only such forms of entry as are traced in areas 70,76 , and 78 are embodied (see example 9); note also the use of the dotted lines in areas 10 , (22), 23 , and 31 for the formatting of an analytical entry.

The examples above are designed for original cataloging; the same format is to be key punched from LC copy, edited as shown in example 10.

The advantages and disadvantages of computerized cataloging can be synthesized in a system based on the best of traditional intentions plus new functions which only the computer can achieve with reasonable economy. These advantages include elimination of some clerical 
$1234567891011121214151617181920212223242526272829303132333435363738394041424344454647484930515253 \quad 65 \quad 67686970$

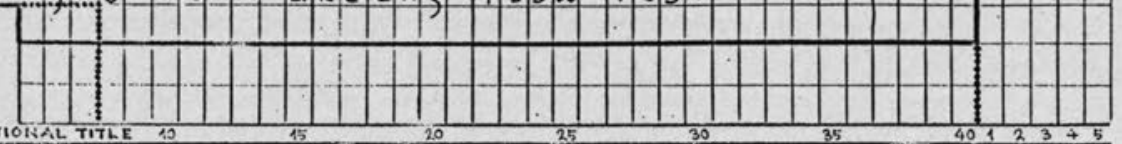

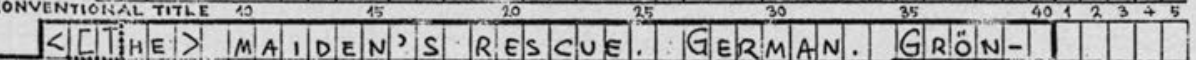

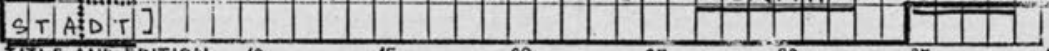

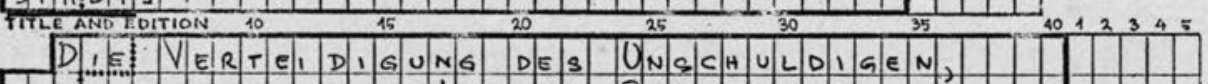

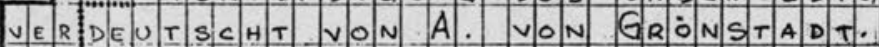

I I I 10 D \begin{tabular}{ll}
\hline+5 \\
\hline
\end{tabular}

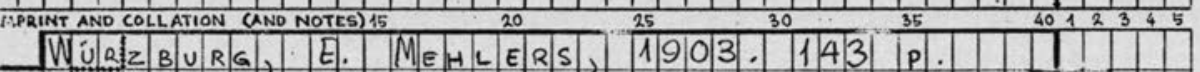
TIOT \begin{tabular}{|l|l|l|l|l|l|l|l|l|}
\hline \\
\hline
\end{tabular}

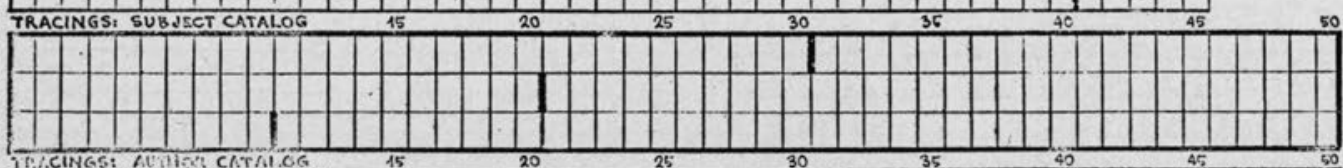

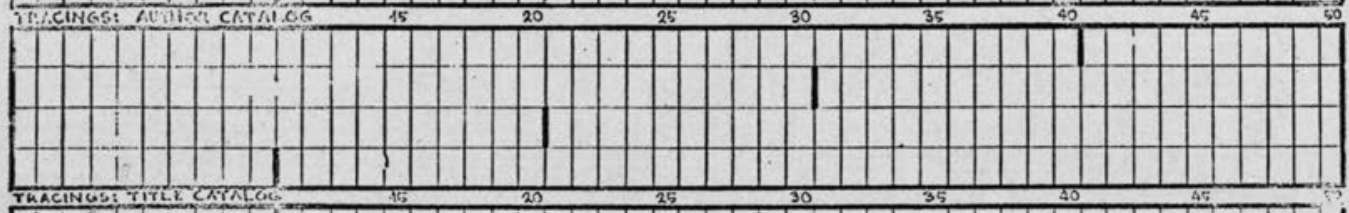

\section{\begin{tabular}{|l|l|l|l|l|l|l|l|l|l|l|l|l|l|l|}
\hline-1 &
\end{tabular}}

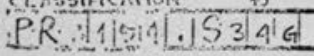

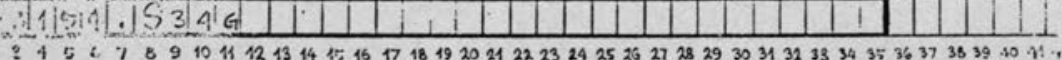

\begin{tabular}{|l|l|l|}
\hline 1 & 0 & 0 \\
\hline 1 & 0 & 1 \\
\hline 1 & 0 & 2 \\
\hline 1 & 0 & 3 \\
\hline
\end{tabular}

2120

\begin{tabular}{|l|l|l|l|}
\hline 2 & 2 & 1 \\
\hline
\end{tabular}

$2{ }^{6 / 3} 10$ \begin{tabular}{llll}
2 & 3 & 1 \\
\hline
\end{tabular} 232 233 \begin{tabular}{llll}
2 & 3 & 4 \\
\hline
\end{tabular} \begin{tabular}{ll}
\hline 2 & 5 \\
\hline 2 & 5
\end{tabular} \begin{tabular}{ll|l}
\hline 31 & 0 \\
\hline
\end{tabular} \begin{tabular}{lll}
\hline 3 & 1 & 1 \\
\hline
\end{tabular} 312 \begin{tabular}{lll}
\hline 3 & & 3 \\
\hline
\end{tabular} \begin{tabular}{lll}
3 & 1 & 4 \\
\hline
\end{tabular} 65 7010 \begin{tabular}{|l|l|l|}
\hline 7 & 0 & 1 \\
\hline 7 & 0 & 2 \\
\hline
\end{tabular}

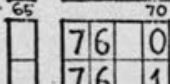
\begin{tabular}{ll|l}
\hline 7 & 6 & 1 \\
\hline 7 & 6 & 2 \\
\hline
\end{tabular} \begin{tabular}{lll}
\hline 76 & 3 \\
\hline
\end{tabular} 780 \begin{tabular}{lll}
7 & 18 & 1 \\
\hline
\end{tabular} $\frac{10}{6070}$ [G] ROE EDDUA[31]

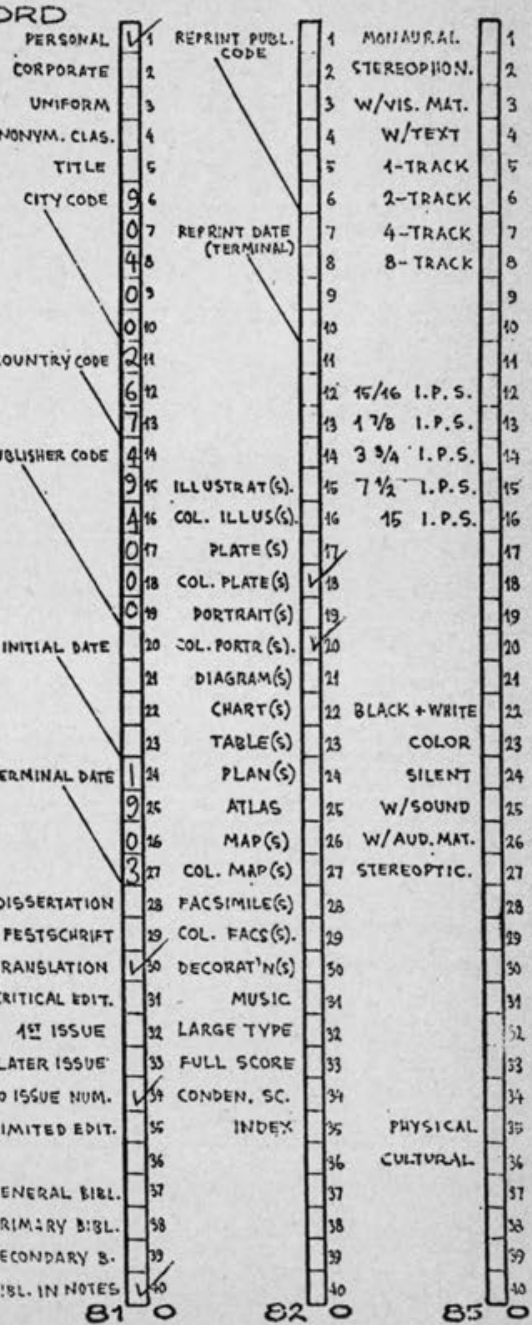

EXAMPLE 1 


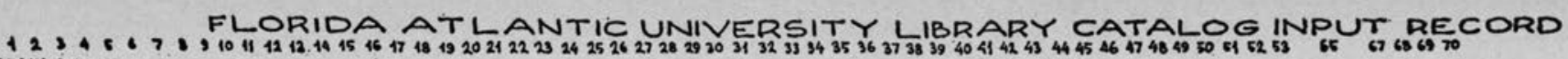

MAIN inTRY

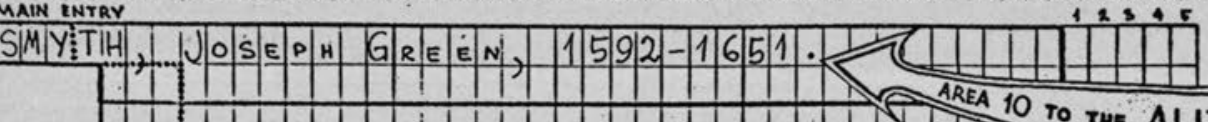

10 SMYTH, Joseph Green, 1592-1651.

H. H H H H

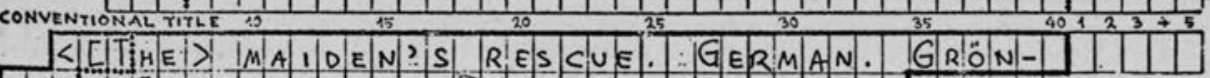

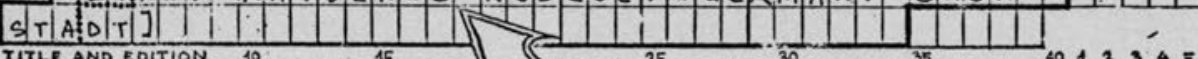

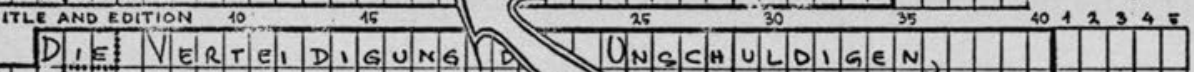

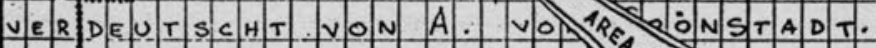

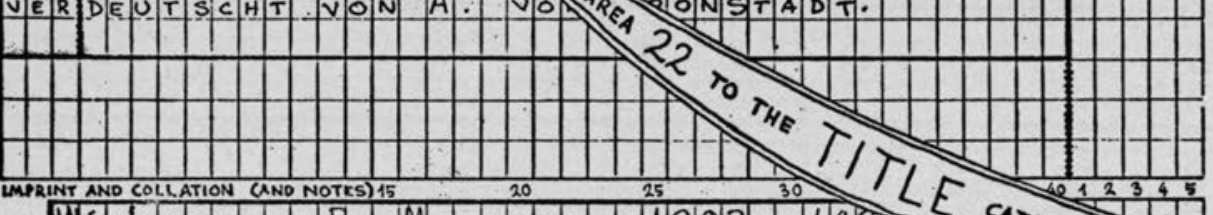
WuRzBURG, E. MEHLERS, 1903 , 143 CATALOG \begin{tabular}{|l|l|l|l|l|l|l|l|l|l|l|l|l|}
\hline & & & & & & & & & & & & \\
\hline
\end{tabular} The malden's rescue. German. Gronstadt] TH

TRACINGSI SUBJECT CATALIOG

Die Verte1digung des Unschuldigen,

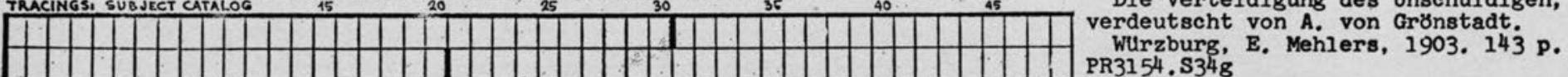

Wurzburg, E. Mehlers, 1903. 143 p. T1 10 H TRACINGS: AUTHOR CATALOG

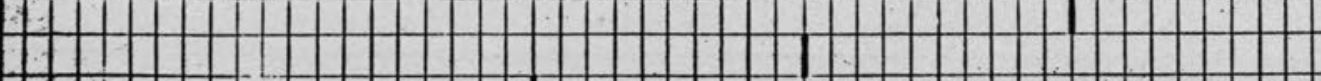

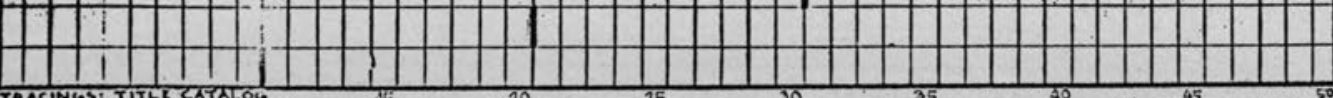

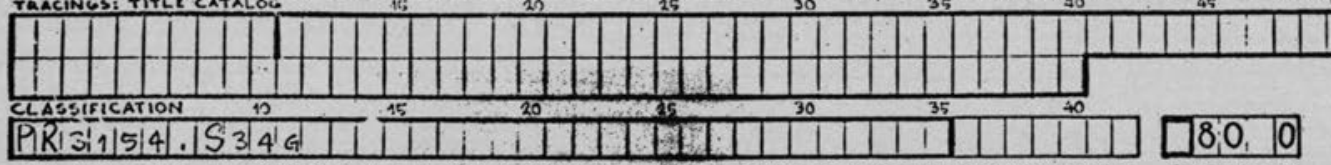
$11710\rfloor$

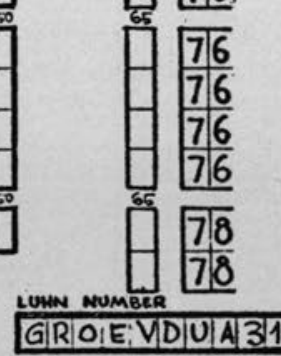




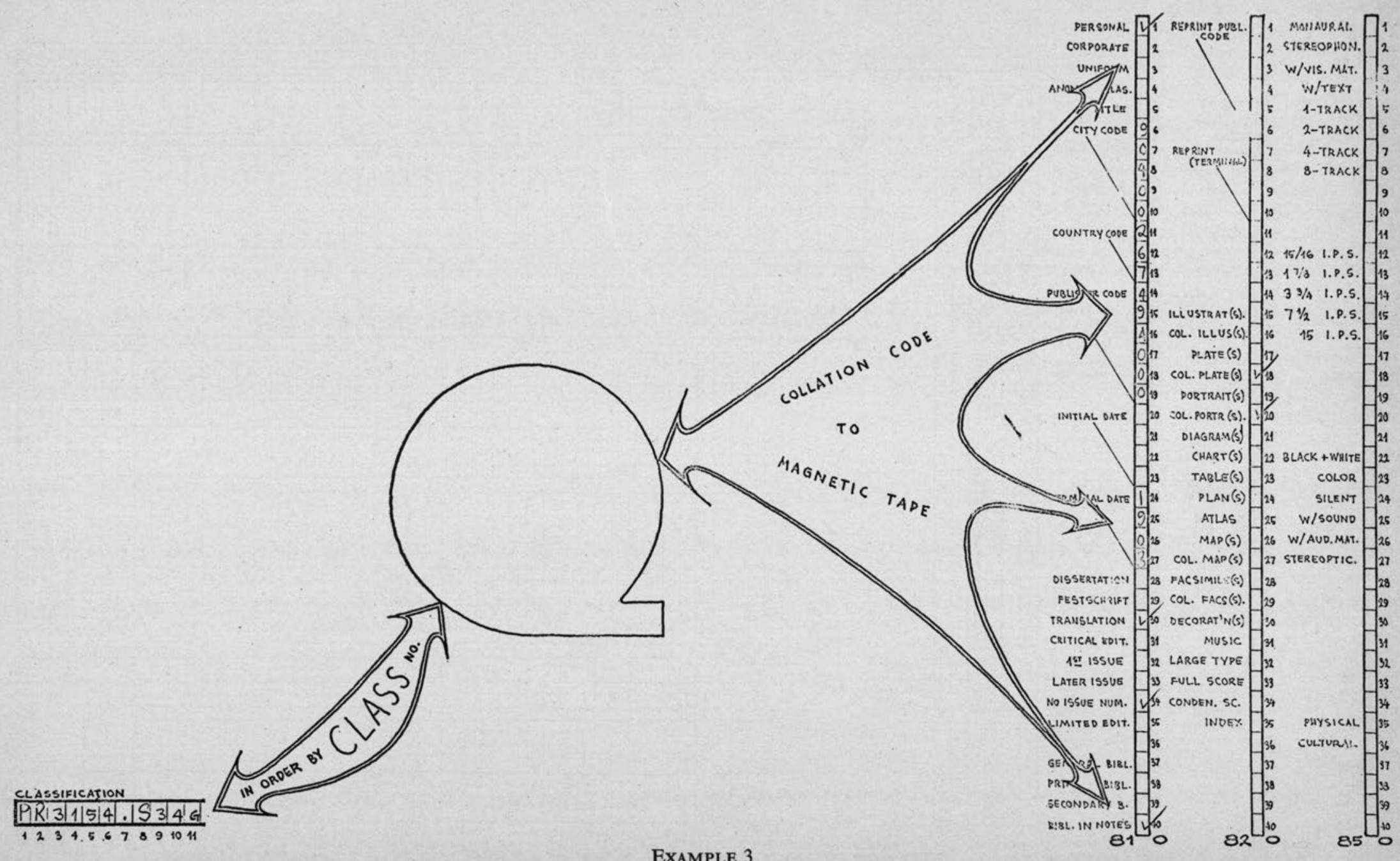


FLORIDA ATL ANTIC UNIVERSITY LIBRARY CATALOG INPUT RECORD

122345

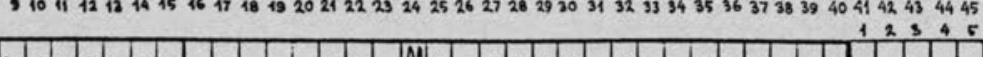

MAIN ENTRY

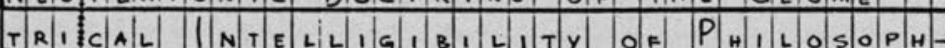

CONVENT

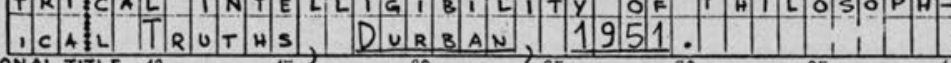

TITLE AND EDITION 10 (10

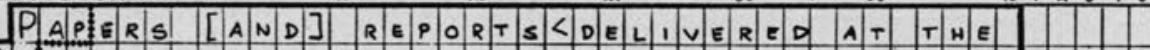

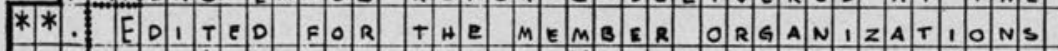

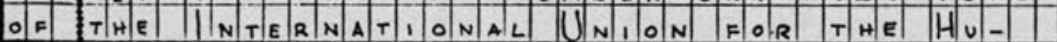

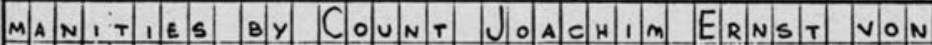

K, I E L S HE I M-MÖLL L E D D O R F F

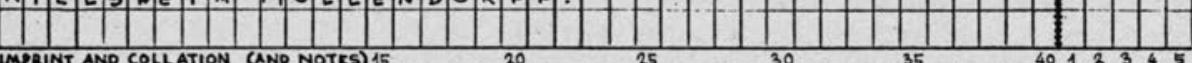

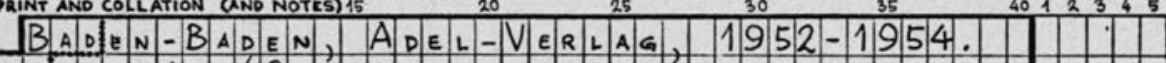

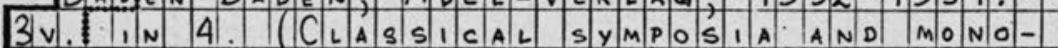

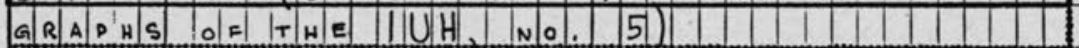

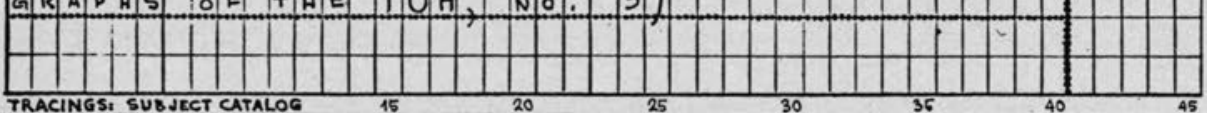

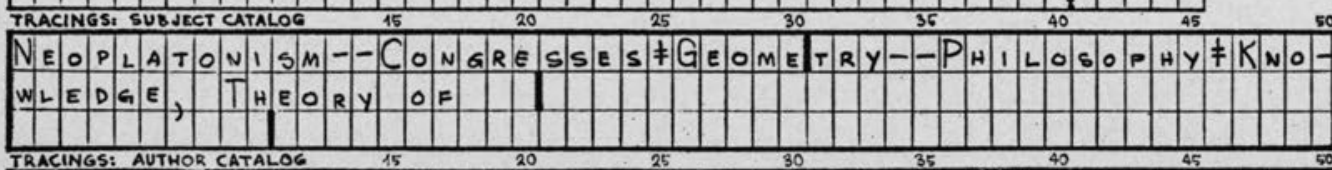

KIIELSHE IM- MOLLLENDORFF, JOOACE $1902-E D$

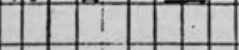

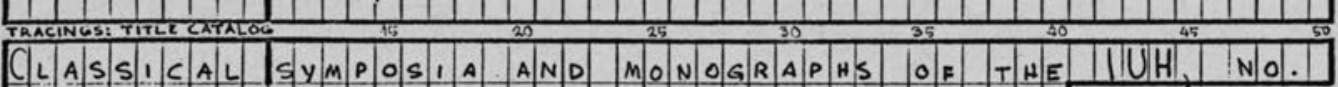

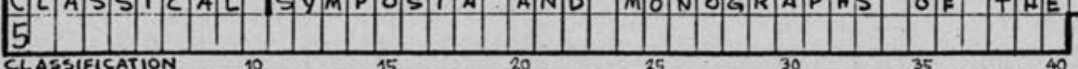

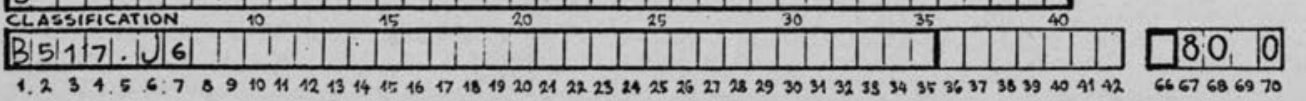

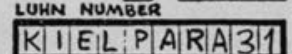

74727374767677787980 persomal

CORPORATE ANIFORM

CITYCODE

$\begin{array}{lll}1 & 0 & 3\end{array}$

\begin{tabular}{|l|l|l|}
\hline 2 & 2 & 0 \\
\hline 2 & 2 & 1 \\
\hline
\end{tabular}

$\begin{array}{lll}2 & 2 & 1\end{array}$

\begin{tabular}{|l|l|l|}
\hline 2 & 3 & 0 \\
\hline 2 & 3 & 1 \\
\hline
\end{tabular}

231

233

234

\begin{tabular}{|l|l|}
\hline 2 & 3 \\
\hline
\end{tabular}

$310^{70}$

\begin{tabular}{l|l|l|}
3 & 1 & 1 \\
\hline
\end{tabular}

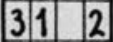

\begin{tabular}{l|l}
3 & 1 \\
\hline
\end{tabular}

\begin{tabular}{|l|l|l|l|}
\hline 3 & & 4 & 4 \\
\hline
\end{tabular}

70 10 701 \begin{tabular}{lll}
70 & 2 \\
\hline
\end{tabular}

dissertation

FESTSCHRIFT

\begin{tabular}{|l|l|}
\hline 76 & 0 \\
\hline 76 & 1 \\
\hline
\end{tabular} 762

$76 \quad 3$

CRITICAL KDIT

LATER ISSUE

No issue num.

UIMITED EDIT.

GENERAL BIZL.

SECONDARY 8.

81

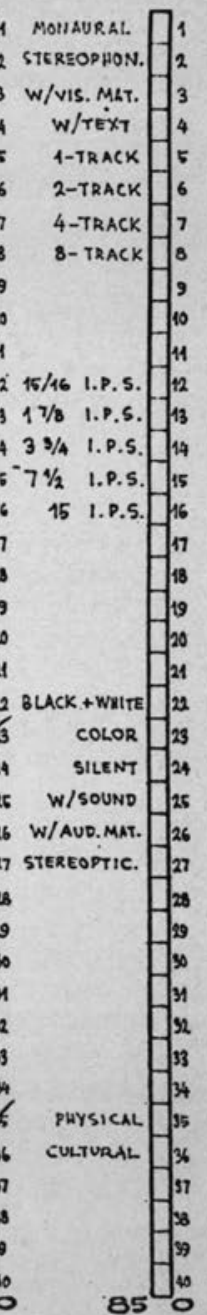

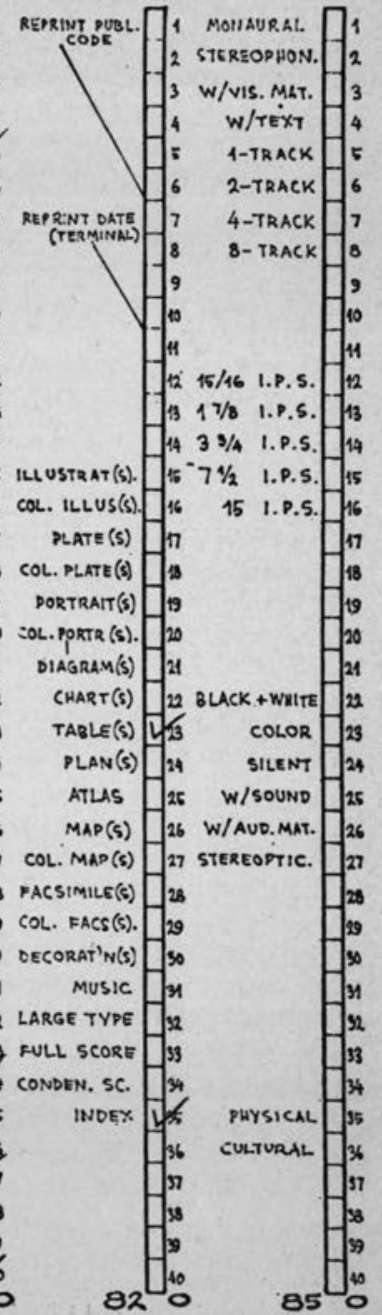




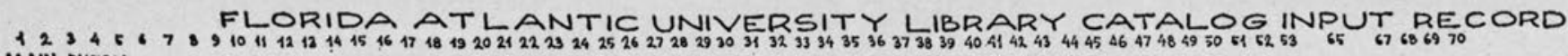

MAIN ENTRY

IOOI:|N|

Ninelo

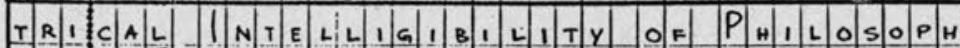

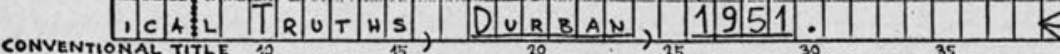

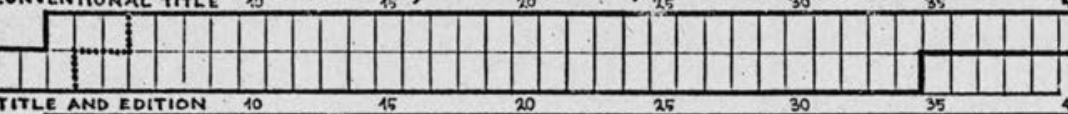

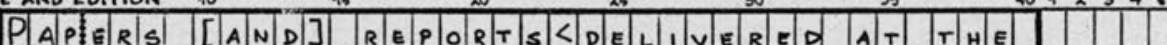

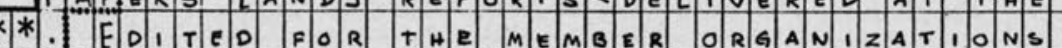

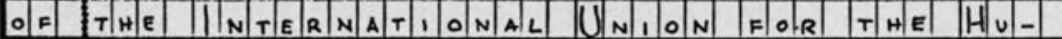

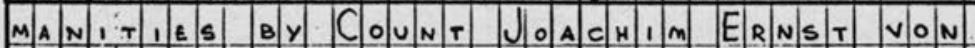

KI E L S H E I M - M ÖLLLE N D O R F F

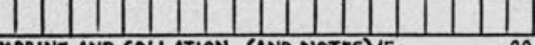

$\frac{1}{25}$

(3)

18

BADDEN-BADEN, A DEL-VER L AG, $1952-1954$.

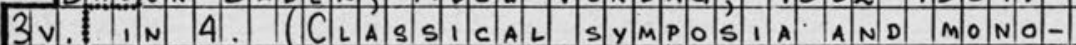

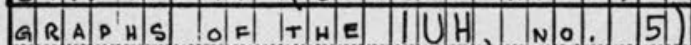

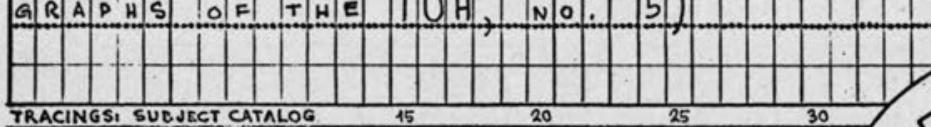

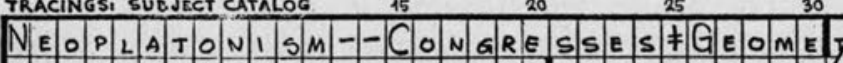
WL

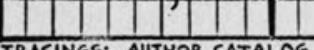

$\frac{1}{15}$

16

$\mathrm{AV} T \mathrm{H}$

UTHOR A11 L.

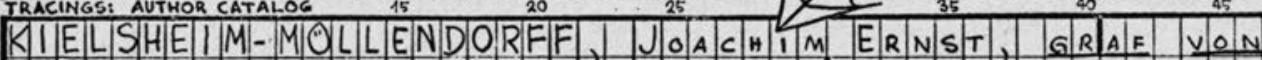

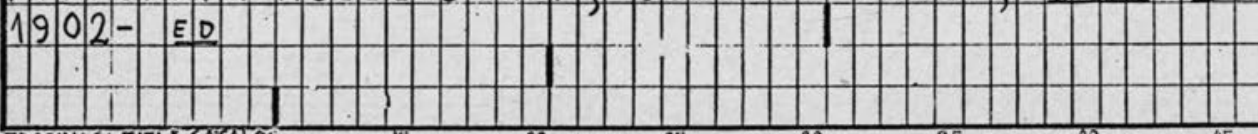

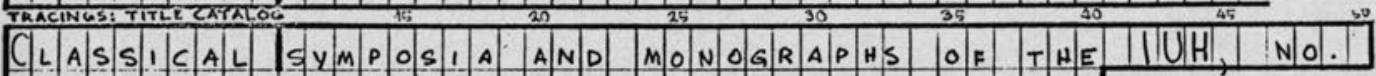

5

CLASSIFICATION

B/5/1/7..J/6

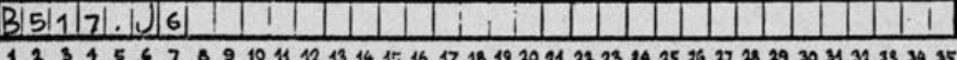

EXAMPLE 5
EX B517. J6

\begin{tabular}{l|l|l|}
\hline 0 & 0 \\
\hline
\end{tabular}
JOINT Symposium on the Meaning of the Neoplatonic Doctrine of the Geometrical Intellig1b1lity of Philosoph 1cal Truths, Durban, 1951.

Papers [and] reports delivered at the **. Ed1ted for the member organizations of the International Union for the Humanities by Count Joach1m Ernst von K1elshe1m-Mollendorff.

Baden-Baden, Adel-Verlag, 1952-1954.

$3 v$. In 4. (Classical symposia and monographs of the IUH, no. 5) B517.J6

KIELSHEIM-MOLLENDORFF, Joach1m Ernst, graf von, 1902- ed. the Geome1cal Truths, Durban, 1951.

Papers [and] reports del1vered at the **. Edited for the member organizations of the International Union for the Humanities by Count Joach1m Ernst von

Kiel she1m-Mollendorff.

Baden-Baden, Adel-Verlag, 1952-1954. 3v. In 4. (Classical symposia and monographs of the IUH, no. 5) 
FL ORIDA ATL ANTIC UNIVERSITY LIBRARY CATALO INPUT PRECORD 12345

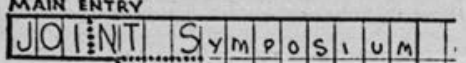

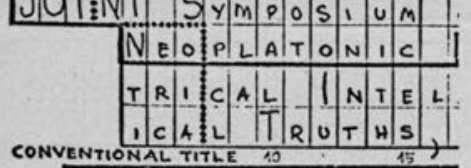

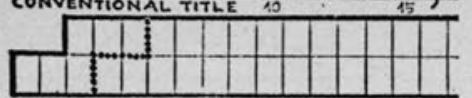

TILE AND EDITION

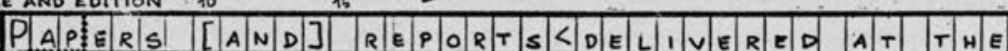

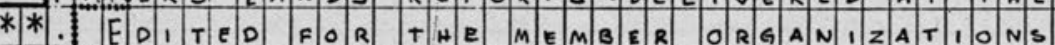

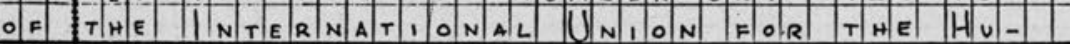

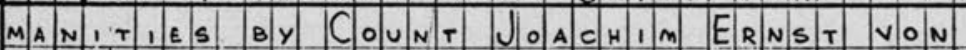

KI E L S U E I M-MÖLL E N D O R F F

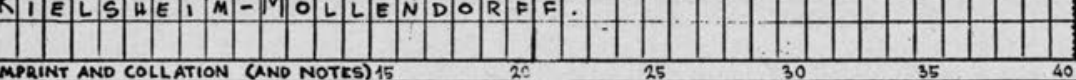

BADDEN-BADEN, A DEL LVIER L A G, $1952-1954$.

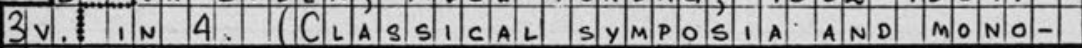

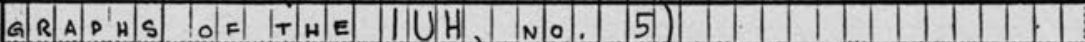

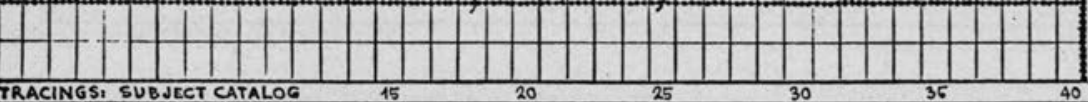

TRACINGS: SUBJECT CATALOG

20

30

$-P$

WL E D G E

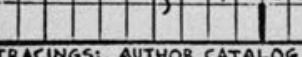

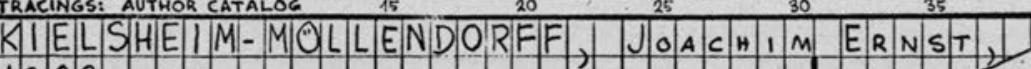
$1902-10$

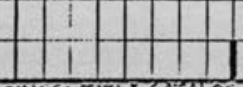

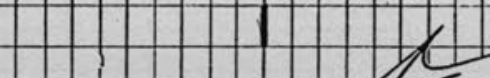

$\coprod_{6}$

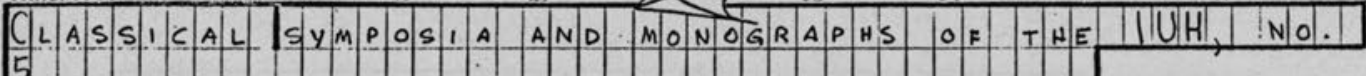

Papers [and] reports.

JOINT Symposium on the Meaning of the

Neoplatonic Doctrine of the Geome-

trical Intelligibility of Philosoph-

1cal Truths, Durban, 1951.

Papers [and] reports delivered at the **. Edited for the member organizations of the International Union for the Humanities by Count Joachim Ernst von

Kiel she1m-Mollendorff.

Baden-Baden, Adel-Verlag, 1952-1954. 3v. In 4 . (Classical symposia and monographs of the IUH, no. 5)

B517.J6

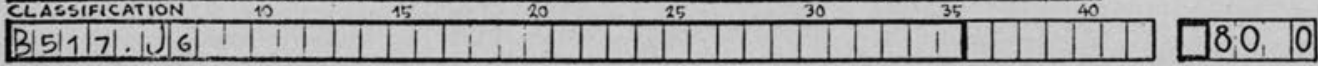

1. $2.34 .56 .789101112131415161718192021222324252627282930313233343536373839404142 \quad 6667686970$

assical symposia and monographs of the IUH. no. 5 .

OINT Symposium on the Meaning of the Neoplatonic Doctrine of the Geometrical Intelligibility of Philosoph1cal Truths, Durban, 1951.

Papers [and] reports deTwered at the **. Edited for the member organizations of the International Union for the Humanities by Count Joachim Ernst von Klelshe1m-Mrilendorff.

Baden-Baden, Adel-Verlag, 1952-1954. 3v. In 4. (Classical symposia and monographs of the IUH, no. 5) B517. J6 


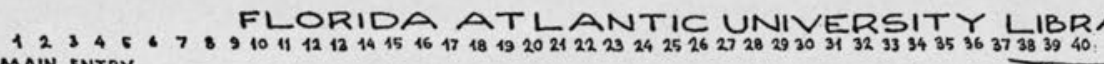

MAIN ENTRY

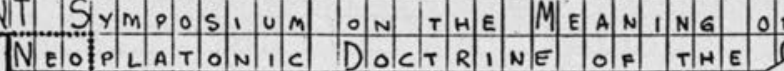

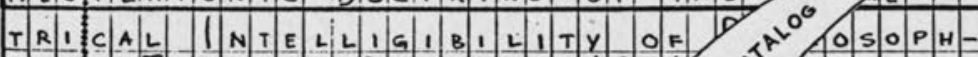

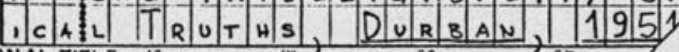

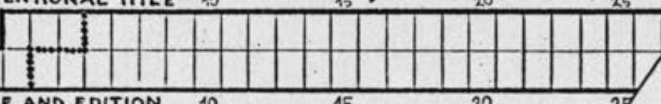

TITLE AND EDITION

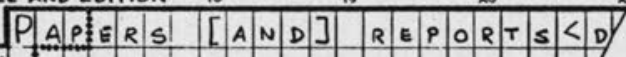

**. E D i t e d f o r t he me m b

- f i t t e

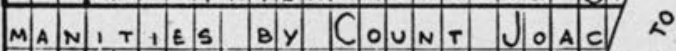

K, E L S HE, M-M ÖL L E N DOR F F

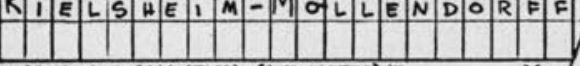

RINT ANO COLLATIO

3V V. $I_{1}$ N 4 .

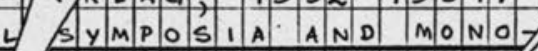

GRA PHS DO ITHE IUUH
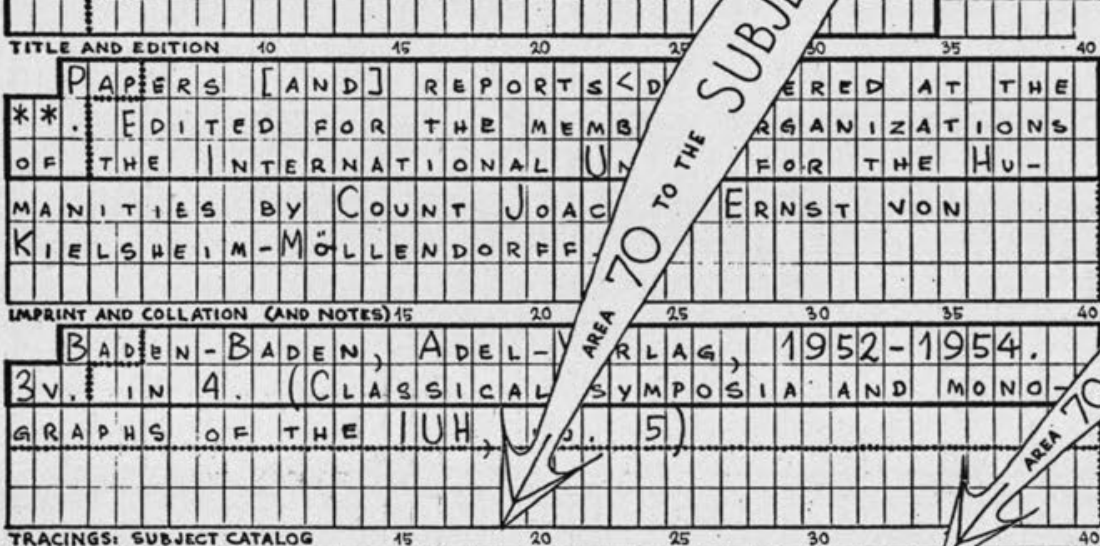

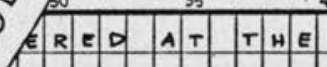

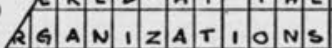

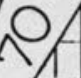

\section{1.}

- tr t hel Hu-

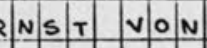
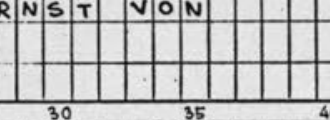

30 30
Bade

\begin{tabular}{ll|l|l|l}
\hline & $T$ & $R$ \\
\hline
\end{tabular} WL E D G E

\begin{tabular}{llllllllllll}
\hline & & & & & & & & & & & \\
\hline
\end{tabular} 15 20
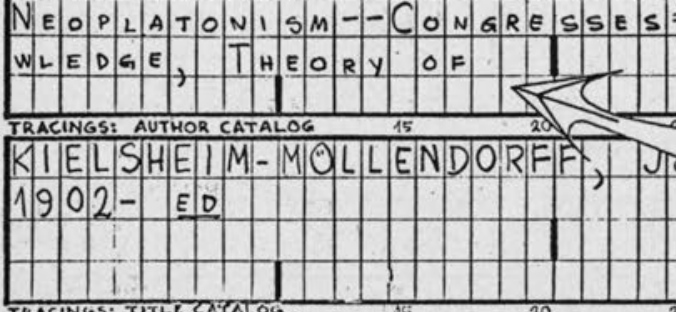

$-1 \mathrm{P}$

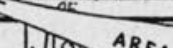

$A R E^{2}$ 70 ,
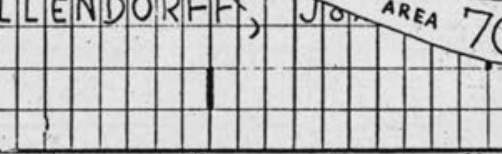

${ }_{5}^{\circ}$

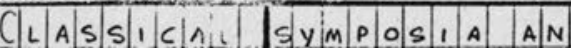
CLASSIFICATIOO

Bi.5|1/7|.1. 6

1234567891011421314151617181920212223242526272829303432333435363738394041.42
Neoplaton1 sm--Congresses.

RECORD INT Symposium on the Meaning of the Neoplatonic Doctrine of the Geometrical Intelligibility of Philosoph1cal Truths, Durban, 1951.

Papers [and] reports delivered at the **. Ed1ted for the member organizations of the International Union for the Humanities by Count Joach1m Ernst von K1elshe1m-Mollendorff.

Baden-Baden, Adel-Verlag, 1952-1954.

$3 v$, in 4. (Classical symposiz and monographs of the IUH, no. 5)

B517. J6
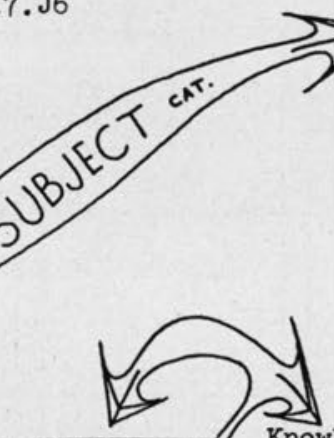

Geometry - Ph1losophy.

INT Symposium on the Meaning of the Neoplatonic Doctrine of the Geome. trical Intelligibility of Philosoph 1cal Truths, Durban. 1951.

Papers [and] reports delivered at the **. Edited for the member organizations of the International Union for the Hu-

manities by Count Joach1m Ernst von Klel she1m-Mollendorff.

Baden-Baden, Adel-Verlag, 1952-1954. 3v. In 4. (Classical symposia and monographs of the IUH, no. 5) B517. J6

Knowledge, Theory of

JOINT Symposium on the Meaning of the Neoplatonic Doctrine of the Geometrical Intelligibility of Philosoph1cal Truths, Durban, 1951.

Papers [and] reports delivered at the ** Edited for the member organizations of the International Union for the Hu manities by Count Joachim Ernst von Kielshe1m-Mollendorff.

Baden-Baden, Adel-Verlag, 1952.1954. 3v. In 4. (Classical symposia and monographs of the IUH, no. 5) B517. J6 
FLORIDA ATL ANTIC UNIVERSITY LIBRARY CATALOG INPUT RECORD $12345678,1011121214151617181920212223242526272829303132333435363738394041424344454647484930515253 \quad 65$ 67 68 6970

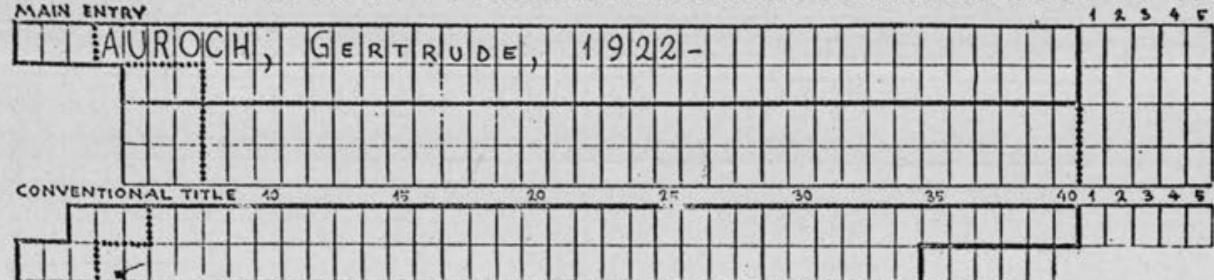

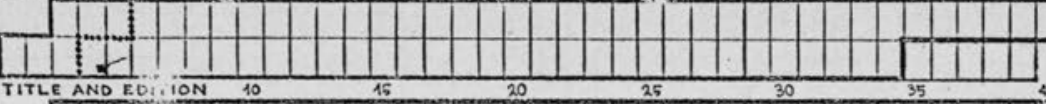

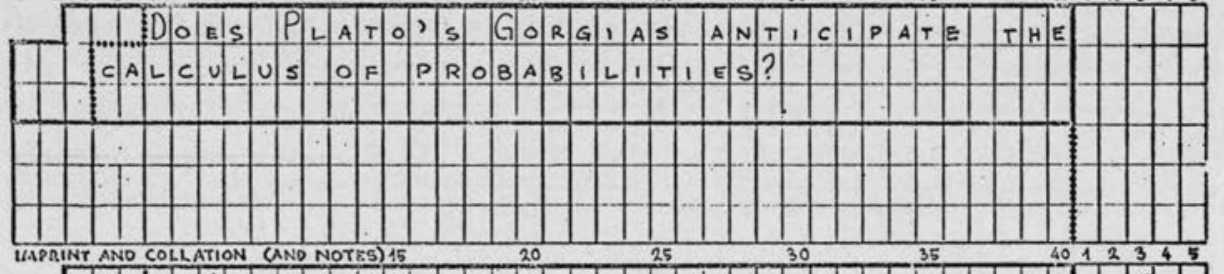

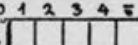
UAPRINT AND COLLATION CAND NOTES) 15 20

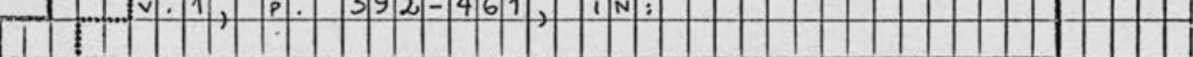
\begin{tabular}{|l|l|l|l|l|l|l|l|l|}
\hline \\
\hline 1
\end{tabular}

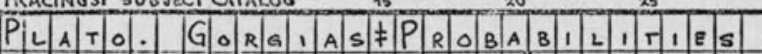
$1+0$ - 100 1 1 . LI - I L

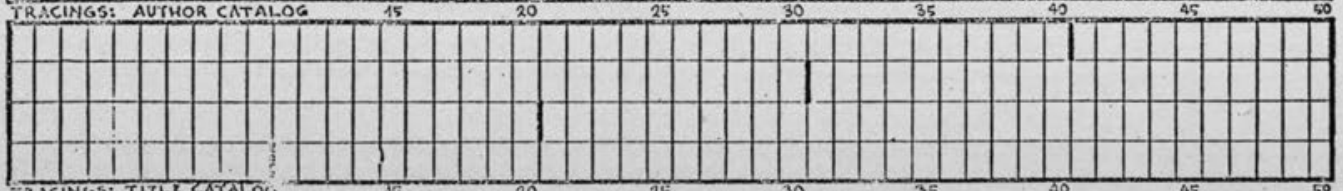

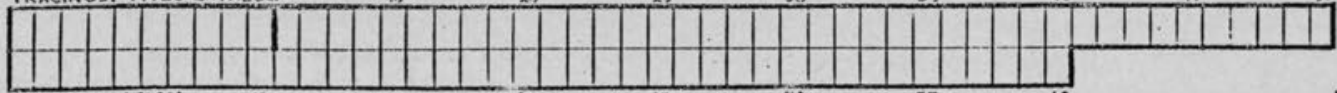
$\frac{\text { CLASSIFICATION }}{1.2311|7| \cdot|\mathrm{J}| 6 \mid}$$$
\text { . }
$$ 


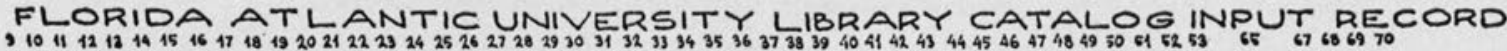
\begin{tabular}{llll}
12 & 3 & 4 & 5 \\
MAIN ENTRY & & 0 \\
\hline
\end{tabular}
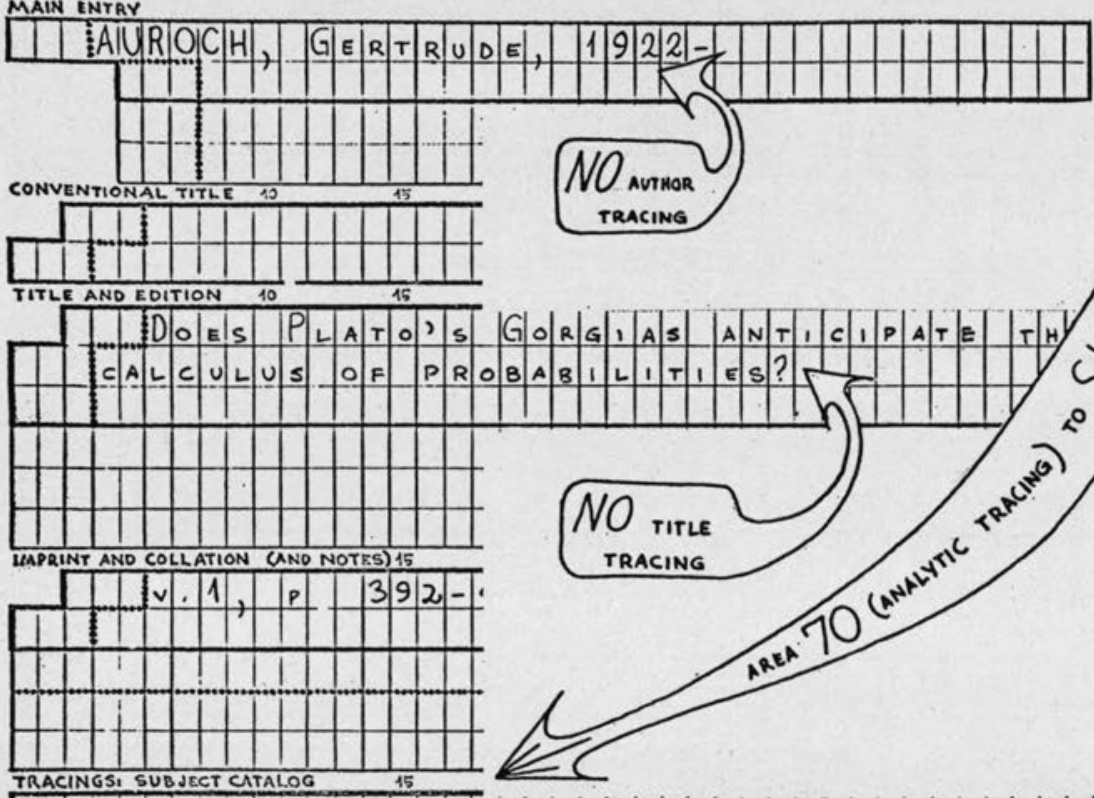

\section{$+$ \\ 11}
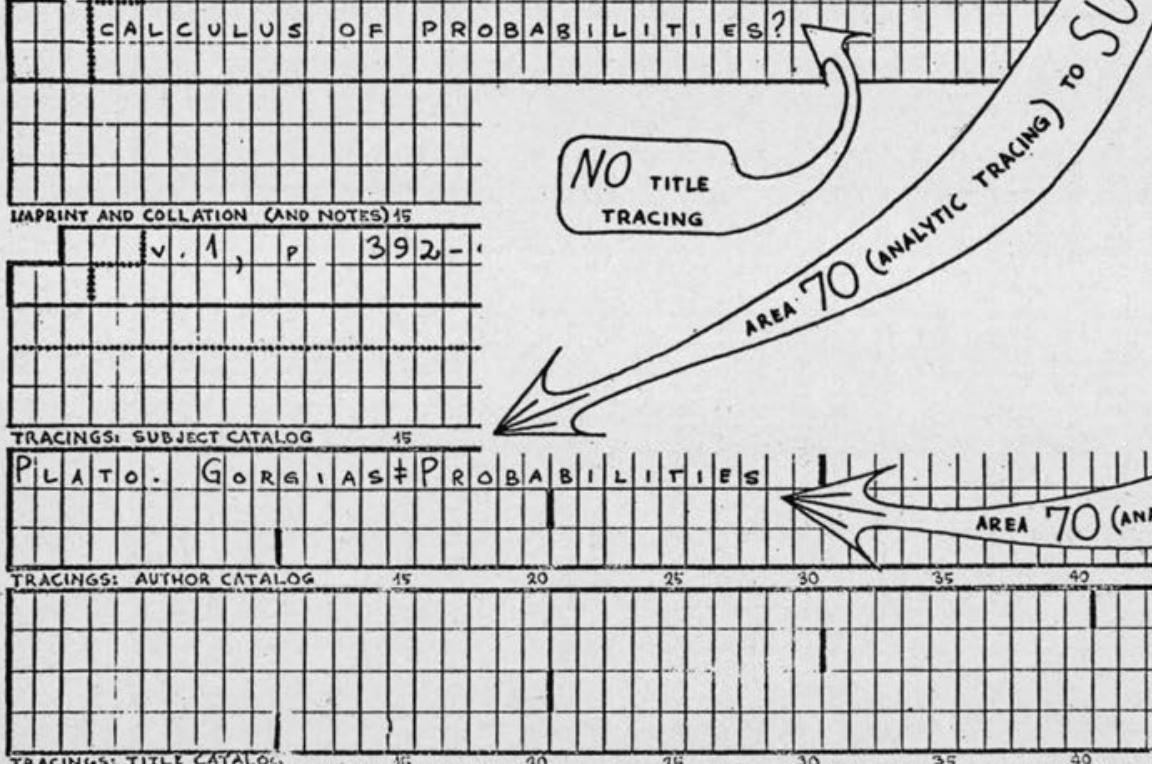

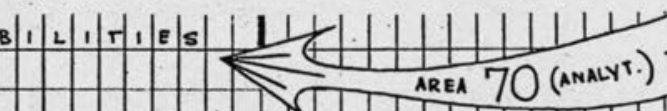

т.) $\mathrm{ro}$
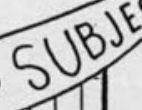

\footnotetext{
T1
}

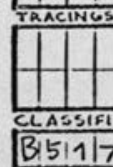

P1ato. Gorg1as. AUROCH, Gertrude, 1922.

Does Plato's Gorg1as anticipate the calculus of probabilities? v. 1, p. $392-461$, 1n:

JOINT Symposium on the Meaning of the Neoplatonic Doctrine of the Geome. trical Intelligibility of Philosoph1cal Truths, Durban, 1951.

Papers [and] reports del1vered at the **. Ed1ted for the member organizations of the International Union for the Humanit1es by Count Joach1m Ernst von K1elshe1m-Mollendorff.

Baden-Baden, Adel-Verlag, 1952-1954. 3v. In 4. (Classical symposia and monographs of the IUH, no. 5) B517.J6

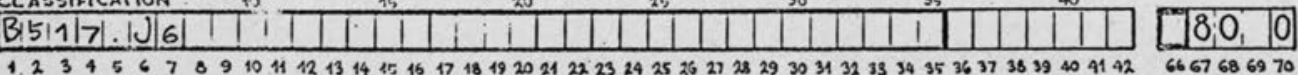

Probab1lit1es.

AUROCH, Gertrude, 1922

Does Plato's Gorgias anticipate the calculus of probabilities?

v. 1, p. 392.461 , 1ns

JOINT Symposium on the Meaning of the Neoplatonic Doctrine of the Geometrical Intelligibility of Ph1losoph 1cal Truths, Durban, 1951.

Papers [and] reports del1vered at the **. Edited for the member organizations *f. the International Union for the Humanities by Count. Joach1m Ernst von K1elshe1m-Möllendorff.

Baden-Baden, Adel-Verlag, 1952-1954. 3v. In 4. (Classical symposia and monographs of the IUH, no. 5) B517.J6 


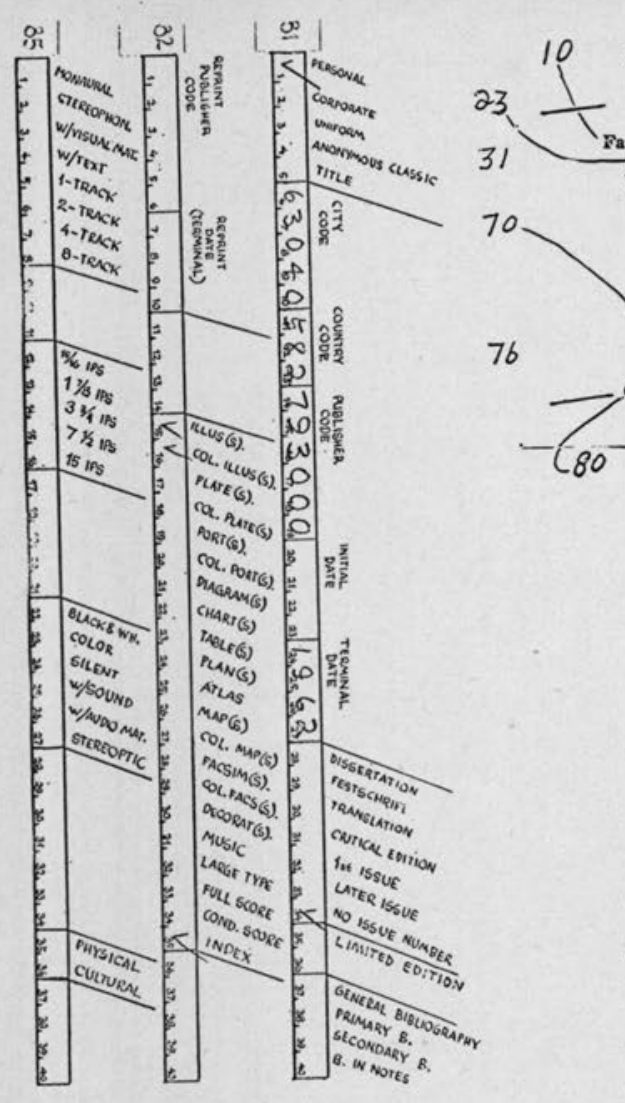

staff (as well as elimination of the possibility of unintended variation), increase of speed (with correspondingly smaller lag between current input and output), and better control than is possible with the conventional official card system. The disadvantages often pointed out are overrigidity, low quality physical results, and the difficulty of changeover. These must be successfully synthesized in a working system that can serve as an efficient medium for research before the inertia of the majority of catalogers can be expected to break down.

An important element in this resolution is a widening of the gamut of output print over that which many fear is a necessary concomitant of IBM implementation, or even of any computer-printer. The limitations of normal IBM print are

narrow: forty-eight characters (twenty-six upper case alphabetical, ten numerical, twelve punctuation and special, many of the latter unuseable for library purposes). By the addition of twenty-six lower case alphabetical characters, and by the substitution of twenty-two punctuation and diacritical characters for the normal twelve, we have devised a new printgamut of eighty-eight characters, capable of reproducing all but a tiny fraction of the characters needed to catalog a multilingual research collection. This, it is hoped, will lift the stigma of mechanicalness and unsophistication from computer printing of library catalogs.

There is another thesis and antithesis that must be synthesized: The thesis is "bibliographical integrity" (a phrase of Kilgour's), the good tradition of cataloging practice as built up over the long period of formulation of our "bibliographic string." The antithesis is the need, in a system which must build to a large volume of entries in a relatively short time, for the catalog to abandon its nonessential infatuation with "pure" bibliography, the need for a theory to emerge of the catalog as a finding list. This is not a finding list theory as a total antithesis to "pure" bibliography, since without bibliographical information there cannot be constructed a finding list with which to find bibliographical items, but it is rather a finding list theory as a synthesis be- 
tween these poles. This is what Florida Atlantic University's system aims at; if it achieves this as well as the synthesis between the advantages and disadvan- tages of the computer, the efforts at University of Illinois, Chicago and Florida Atlantic University will be vindicated.

\title{
Cataloging for Document Retrieval at Florida Atlantic University
}

\author{
BY CLAYTON D. HIGHUM
}

INCLUDED in the cataloging of library materials at Florida Atlantic University is a procedure which involves the coding of specific information for the purpose of later retrieval of these materials. This coding is done on the same transmittal sheet that is used for the descriptive cataloging of materials for the computer-produced book catalog. As is indicated in the form reproduced here, three fortyspace columns are utilized for the coding of the desired information. The entire procedure may be described quite accurately as an expansion of the collation and imprint of a document. The reason for the forty-space columns instead of the eighty-space columns of the typical IBM data processing card is that the length of each column was determined somewhat by the availability of space on the transmittal sheet. Also, future expansion of the procedure will be possible without a complete reformatting of the transmittal sheet.

Some explanation for the use of the term "document" in this article might be in order. The reader will realize that the coding areas on the transmittal form include many elements not ordinarily associated with a document. First, for lack of a better term, "document" is used. Second, the retrieval discussed in this article includes types of materials other than the typical document. The library at Florida Atlantic University is an integral part of the Learning Resources Di-
Mr. Highum is Assistant Librarian in Cataloging at Florida Atlantic University.

vision, and as such the catalog will include all materials, book and nonbook, that comprise the collection of the entire division. Therefore, rather than attempting continually to differentiate among the many forms of material included on the coding sheet, the word "document" is being used as an all-inclusive term.

Most of the fields represented on the coding sheet are self-explanatory. Therefore, no detailed explanation will be given here. Detailed instructions have been developed, however, and are given to the catalogers to assist them in the coding.

In general terms, each labeled space that can be associated with the document being cataloged is either checked or filled with an appropriate, pre-established code. The only limit to the number of spaces checked is the document being cataloged. It is assumed that the catalogers will analyze each piece of material carefully enough to insure adequate coverage. Obviously, the more specific the analysis, the more meaningful and worthwhile a retrieval becomes to the patron. Some blank spaces have been left on the form to allow for future expansion or for the addition of elements that were forgotten or not justified for inclusion at the time the form was developed.

Field 1-5 in area 81 provides space for the indication of the type of main entry 